\title{
Ovarian Mucinous Cystadenoma Presenting as Pseudo-Meigs Syndrome
}

\author{
GAZI KHAN MD. SHAHIDUZZAMAN, ${ }^{1}$ PORITOSH KUMAR CHOWDHURY ${ }^{2}$, BISHNUPADA PAIK ${ }^{3}$, SANKAR PROSHAD \\ BISWAS $^{4}$, RAFIQUL ISLAM 5
}

\begin{abstract}
:
Meigs syndrome is defined as the co-existence of benign ovarian tumor with ascites and hydrothorax that resolves after resection of tumor. The ovarian tumor in Meigs syndrome is fibroma. On the contrary, Pseudo-Meigs syndrome is characterized by the co-existence of hydrothorax, ascites and ovarian tumor either benign or malignant other than ovarian fibroma. The case herein concerns a 70 year old postmenopausal woman presented with the complaints of progressive shortness of breath on exertion and progressive swelling of lower abdomen. Her clinical and radiological examination revealed a massive right sided pleural effusion, mild ascites and a large heterogeneous pelvic mass with solid and cystic components, suggestive of left ovarian tumor. The patient underwent an exploratory laparotomy with excision of tumor, right ovary and whole of the uterus. The tumor was diagnosed histologically as an ovarian mucinous ystadenoma. Postoperative resolution of hydrothorax and ascites confirmed the diagnosis of Pseudo-Meigs syndrome.
\end{abstract}

Keyword: Pseudo Meigs syndrome

\section{Introduction:}

The co-existence of pelvic tumor, hydrothorax and ascites has been known since the late $19^{\text {th }}$ century. The features of the disease were described by Meigs and Cass in $1973 .{ }^{1}$ In the same year Roads named it "Meigs syndrome". Today, Meigs syndrome is defined as the co-existence of benign ovarian fibroma, hydrothorax and ascites. On the contrary, Pseudo-Meigs syndrome is characterized by the coexistence of hydrothorax, ascites and other ovarian- usually malignant or pelvic tumors. Both these syndrome should be considered in otherwise healthy postmenopausal women, who present with either new or recurrent hydrothorax or ascites. The preoperative differential diagnosis between them is useless, since the surgical resection of the tumor is the only therapeutic choice, resulting to the resolution of fluid accumulations in both the situations. ${ }^{2}$

1. Senior Consultant, Medicine, Khulna Medical College Hospital, Khulna.

2. Assistant Professor, Respiratory Medicine, Khulna Medical College Hospital, Khulna.

3. Assistant Professor, Gastroenterology, Khulna Medical College, Khulna.

4. Assistant Professor, Gynae \& Obs, Khulna Medical College, Khulna.

5. Assistant Registrar, Medicine, Khulna Medical College Hospital, Khulna.

Correspondence: Dr. Gazi Khan Md. Shahiduzzaman, Senior Consultant, Medicine Khulna Medical College Hospital, Khulna, E-mail: dr.shahiduzzaman@yahoo.com

\section{Case Report:}

Mrs. Rabeya a 70 year old postmenopausal woman admitted in Medicine unit-IV in December 2010 because of progressive shortness of breath on exertion and progressive swelling of lower abdomen for the last 6 months. She was afebrile and did not give any history of chest tightness, cough, wheezing or night sweats. The lower abdomen was not associated with pain, per-vaginal discharge, bowel and bladder disturbance. There was no history of itching of the body, pain in bones or joints or significant weight loss during the course of the illness.

Physical examination revealed right sided massive pleural effusion, mild to moderate ascites and a large irregular mass arising from pelvis. $\mathrm{P} / \mathrm{V}$ examination revealed a rounded pelvic mass separated from the uterus and there was also $2^{0}$ uterine prolapse with $2^{0}$ old tear with cystocele and rectocele. A massive right pleural effusion was found at chest $\mathrm{x}$-ray (Fig.-1). Ultrasonogram of abdomen demonstrated mild ascites and a large heterogeneous, with solid and cystic components, pelvic tumor measured $(20 \mathrm{cmX} 15 \mathrm{~cm})$ suggestive of left ovarian mass.

These findings were combined with mild anaemia ( $\mathrm{Hb}$. Conc: $10.5 \mathrm{gm} / \mathrm{dl}$ ), high ESR (50 $\mathrm{mm}$ in $1^{\text {st }}$ hour), serum CA-125 (32.08 U/ml, NR: $<29.60 \mathrm{U} / \mathrm{ml})$.

A preoperative paracentesis and drainage of pleural effusion was necessary to relieve the patient's dyspenic symptomatology. The fluid was exudative (protein: $5.1 \mathrm{gm} /$ dl) and cytological examination of fluid was negative for malignant cells. Ascitic fluid was also drawn out for study 


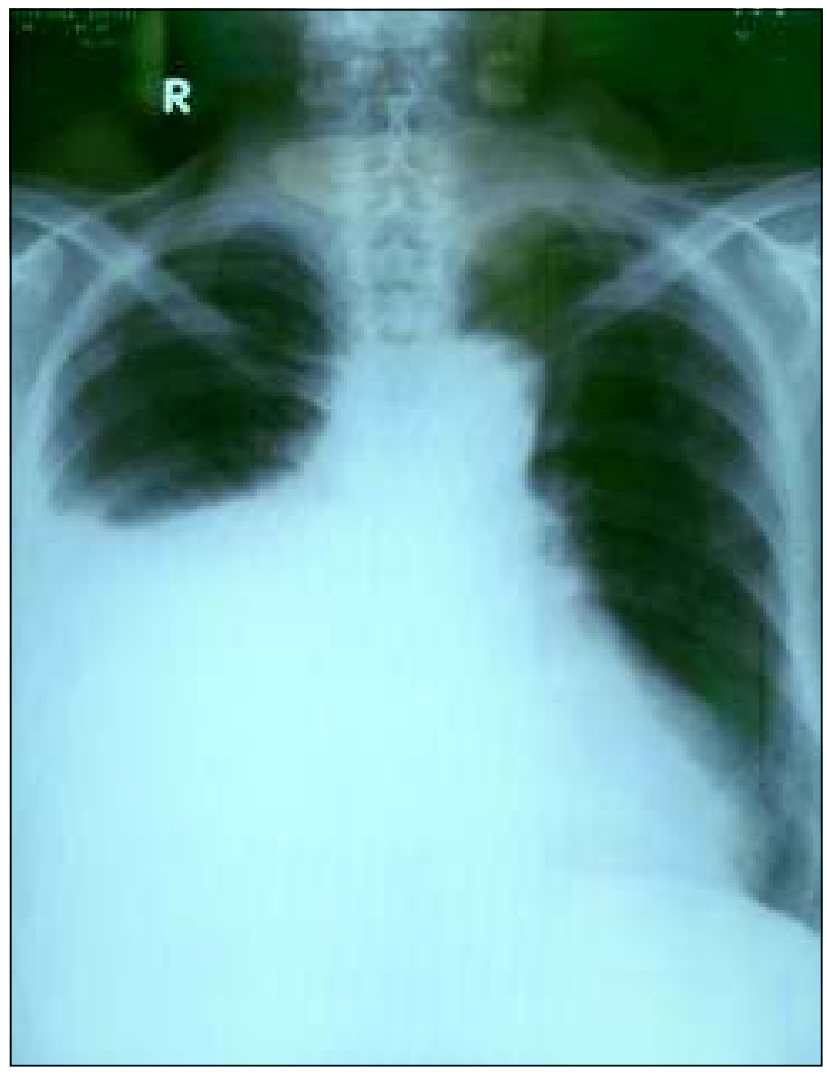

Fig.-1: $X$-ray chest showing massive right sided pleural effusion.

and it was also exudative (protein $3.8 \mathrm{gm}$. /dl) and cytological examination of the fluid was negative for malignant cells.

The patient underwent an exploratory laparotomy with excision of tumor, right ovary and whole of the uterus. Macroscopic picture of resected tumor is shown in Fig.-2. The tumor was diagnosed histologically as an ovarian mucinous cystadenoma.

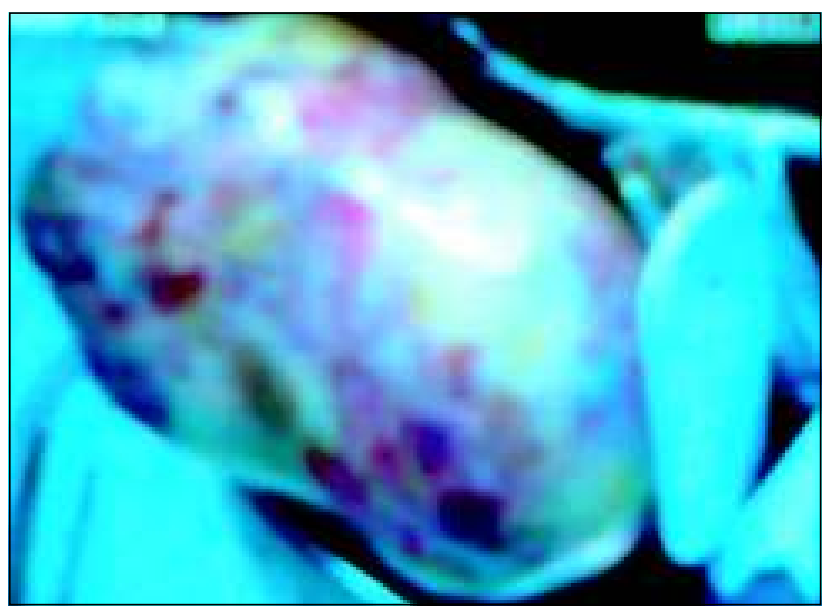

Fig.-2: Macroscopic picture of large left ovarian tumor $(25 \mathrm{~cm} X 15 \mathrm{~cm})$.
Three months later a follow up chest $\mathrm{x}$-ray and ultrasonogram showed resolution of hydrothorax and ascites confirmed the diagnosis of Pseudo-Meigs syndrome (Fig.-2).

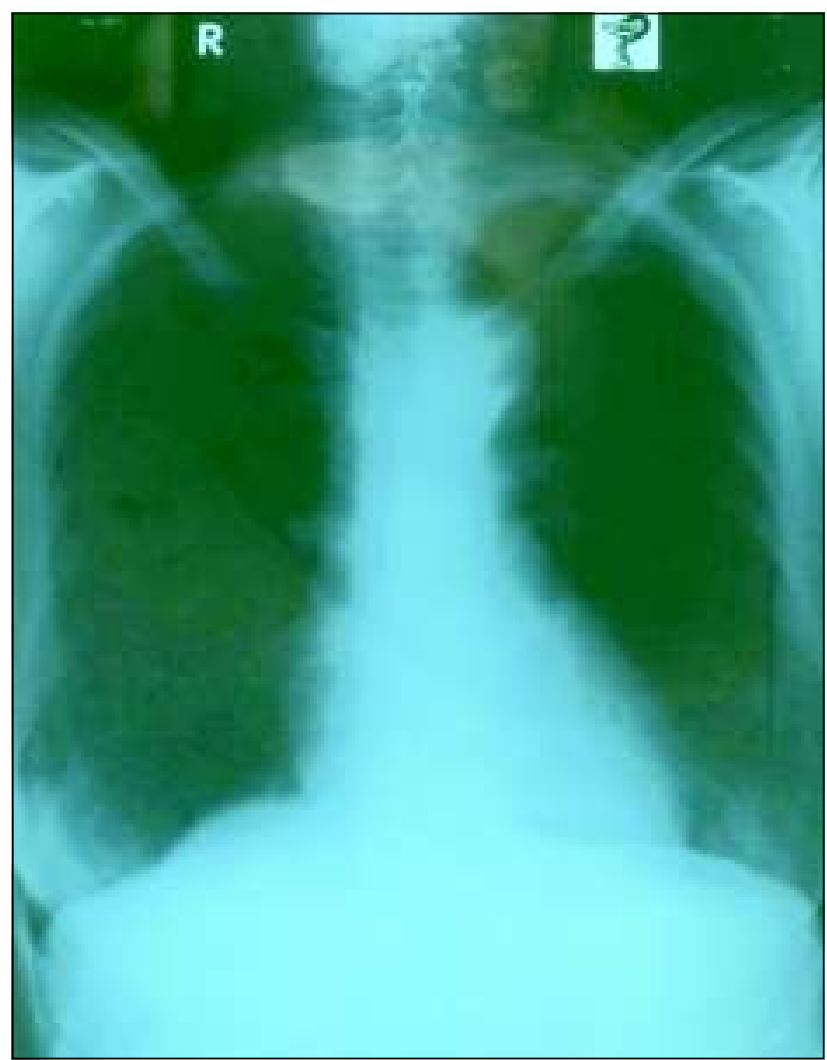

Fig.-3: $X$-ray showing complete resolution of pleural effusion after tumour removal.

\section{Discussion:}

The Pseudo-Meigs syndrome can be combined with either benign or malignant tumors (Table-1).

\section{Table-I}

Common tumors associated with Pseudo-Meigs syndrome.

\section{Benign Tumors}

- Ovarian tumors, other than fibromas

- Stromal tumor

- Struma ovarii

- Teratomas

- Cystadenomas

- Paraovarian fibromas

- Uterine leiomyoma

- Leiomyomas of broad ligament

\section{Malignant Tumors}

- Primary ovarian tomors

- Adenocarcinomas

- Endometrioid carcinomas

- Secondary metastatic ovarian tomors, from primary gastrointestinal cancers 
Etiology of fluid accumulations remains unclear, although it appears to be related to lymphatic obstruction. The most likely pathogenesis of peritoneal and pleural effusions ascribes filtration of interstitial fluid into peritoneum through the tumor capsule, and diffusion to the pleural space, usually at the right side, through diaphragmatic lymphatic vessels and apertures as well as through intercellular gaps and small areas where muscular tissue of diaphragm is replaced by areolar tissues. ${ }^{3,4}$

The majority of ovarian tumors, associated with hydrothorax and ascites, have a diameter more than $6 \mathrm{~cm}$. The entity of effusions can be moderate or massive. The effusions generally derive from a transudative process but occasionally may be exudative. Their connection with pelvic tumor is demonstrated by their regression after neoplasm removal.

Pseudo-Meigs syndrome is clinically important because it resembles metastatic pelvic cancer. Especially in patients with malignant ovarian tumors, cytological examination of body cavity effusion is essential to differentiate between reactive process and metastatic tumor spread. ${ }^{5}$ While detection of malignant cells is a marker of metastatic disease and a sign of bad prognosis, benign effusions of PseudoMeigs syndrome affects neither disease nor the patient's prognosis. Determination of the presence or absence of tumor spread is primarily on cellular morphology study, but if distinction between reactive mesothelium and cancer cells is difficult, immunocytochemistry may be necessary.

At this point, must be underlined that an ovarian mass combined with pleural and peritoneal effusions not always represents an advanced malignancy, even with elevation of CA-125 value. ${ }^{6,7}$ There are some benign pelvic lesions causing pseudo-Meigs syndrome, which are associated with elevated levels of this tumor marker, such as struma ovarii, ovarian cystadenomas, uterine leiomyomas and broad ligament leiomyomas. ${ }^{4,8-14} \mathrm{CA}-125$ levels decline to the normal range after tumor resection.

There also reported 6 cases of Pseudo-Meigs syndrome caused by secondary ovarian tumors from gastrointestinal cancers. ${ }^{15}$ The primary site was the colon or rectum in 5 and stomach in 1. Two cases were due to Krukenberg tumors. Three patients with documented outcomes were alive 108, 52 and 12 months after resections, demonstrating that in these cases resection provide long term palliation.

\section{Conclusion:}

Pseudo-Meigs syndrome should be considered as a rare differential diagnosis for pleural effusion and ascites when a patient is admitted in medicine word. Patients with pseudoMeigs syndrome may present a diagnostic problem as they mimic as carcinoma with malignant effusions. Thus they should always undergone exploratory laparotomy. Surgical therapy has a very important role for the complete remission of the disease in cases of benign tumors, and for the remission of pleural and ascites effusions in cases of malignant tumors.

\section{Conflict of Interest : None}

\section{References:}

1. Meigs JV, Cass JW. Fibroma of the ovary with ascites and hydrothorax: with a report of seven cases. Am J Obstet Gynecol. 1937; 33:249-267

2. Kazanov L, Ander DS, Enriquez E, Jaggi FM. Pseudo-Meigs syndome. Am J Emerg Med 1998; 16 (4): 404-405

3. Santopaolo D, Rotondo A, Alfe M, Canciello P, Rito Marcone G, Cusati B. [Meigs syndrome with bilateral hydrothorax]. Minerva Ginecol 1993; 45 (5): 263-266

4. Amant F, Gabriel C, Timmerman D, Vergote I. PseudoMeigs syndrome caused by hydropic degenerating uterine leiomyoma with elevated CA 125. Gynecol Oncol 2002; 83 (1): $153-157$

5. Wiatrowska B, Krajci P, Berner A. [Pseudo-Meigs syndrome]. Tideskr Nor Laegeforen 2000; 120 (3): 364-3665

6. Santangelo M, Battaglia M, Vescio G, Sammarco G, Galleli G, Vetere A, Sommela L, Triggiani E. [Meigs syndrome: Its clinical picture and treatment]. Ann Ital Chir 2000; 71 (1): 115-119

7. Domingo P, Montiel JA, Monill JM, Prat J. Pseudo-Meigs syndrome with elevated CA 125 levels. Arch Intern Med 1998; 158 (12): 1378-1379

8. Huh JJ, Montz FJ, Bristow RE. Struma ovarii associated with pseudo-Meigs syndrome and elevated serum CA 125. Gynecol Oncol 2002; 86 (2): 231-234

9. Bethune M, quinn M, Rome R. Struma ovarii presenting as acute pseudo-Meigs syndrome with an elevated CA 125 level. Aust N Z J Obstet Gynecol 1996; 36 (3): 372-373

10. Long CY, Chen YH, Chen SC, Lee JN, Su TH. Hsu SC. Pseudo-Meigs syndrome and elevated levels of tumor markers associated with benign ovarian tumors: Two cases reports. Kaohsing J Med Sci 2001; 17 (11): 582-585

11. Kebapci M, Aslan O, Kaya T, T Yalsin O, Ozalp S. Redunculated uterine leiomyoma associated with pseudoMeigs syndrome and elevated CA 125 level: CT features. Eur Radiol 2002; 12: 127-129

12. Migishima F, Jobo T, Hata H, Sato R, Ikeda Y, Arai M, Kuramoto $\mathrm{H}$. Uterine leiomyoma causing massive ascites and left pleural effusion with elevated CA 125: A case report. J Obstet Gynecol Res 2000; 26 (4): 283-287

13. Dunn JS Jr, Anderson CD, Method MW, Brost BC. Hydropic degenerating leiomyoma presenting as pseudoMeigs syndrome with elevated CA 125. Obstet Gynecol 1998; 92 (4): 648-649)

14. Brown RS, Marley JL, Cassoni AM. Pseudo-Meigs syndrome due to broad ligament leiomyoma: A mimic of metastatic ovarian carcinoma. Clin oncol CR Coll Radiol) 1998; 10(3):198-201

15. Nagakura S, Shirai Y, Hatakeyama K. Pseudo-Meigs syndrome caused by secondary ovarian tumors from gastrointestinal cancer: A case report and review of the literature. Dig Surg 2000; 17 (4): 418-419 